\title{
MOBILISASI PENYEBARAN INFORMASI KAMPUS BERBASIS FIREBASE CLOUD MESSAGING (FCM)
}

\author{
Fajar Abdul Aziz*, Munawarah, Primaadi Airlangga
}

Fakultas Teknologi Informasi Universita KH. A. Wahab Hasbullah

Correspondence Author: fajar.abaz@gmail.com

\begin{tabular}{|c|c|}
\hline Info Artikel : & ABSTRAK \\
\hline $\begin{array}{l}\text { Keywords: } \\
\text { Notifikasi, Firebase } \\
\text { Cloud Messaging, } \\
\text { Android, PHP, MySQL }\end{array}$ & $\begin{array}{l}\text { Knowing information is important for students, especially } \\
\text { information about the college. The fame of using SMS gateway as the } \\
\text { information spread media which has much deficiency, such as the needs of } \\
\text { credit as the sending media and cannot searching message. Nowadays } \\
\text { some message delivery media based on Android come up with the lack in } \\
\text { some aspects. For an instant, the user of a group can send a message in } \\
\text { the group's chat rooms so that the important message can jumble with the } \\
\text { other information. } \\
\text { In this research, we will offer an application that is able to give } \\
\text { real time information. The information used one line system so that it } \\
\text { cannot jumble with the other information. The information contain the } \\
\text { alarm that has benefit to remind the user and then the message searching } \\
\text { feature to help the user to look for the previous information, the usage of } \\
\text { website technology as the data organizing be able to be accessed by the } \\
\text { administrator, furthermore the usage of mobile device with android based } \\
\text { can be accessed more easily and also the usage of API from firebase to } \\
\text { send a message in the real time. This research resulted in applications } \\
\text { that can support needs such as providing information specifically in } \\
\text { realtime and have an alarm feature activity. }\end{array}$ \\
\hline
\end{tabular}
INTISARI

Kata Kunci :

Notifikasi, Firebase

Cloud Messaging,

Android, PHP, MySQL
Informasi merupakan hal sangat penting untuk diketahui, terutama infromasi kampus bagi seorang mahasiswa. Masih maraknya penggunaan SMS Gateway sebagai media penyebaran informasi yang memiliki beberapa kekurangan, diantaranya membutuhkan pulsa sebagai media pengirimnya, dan tidak bisa melakukan pencarian pesan. Saat ini juga sudah banyak muncul media pengiriman pesan berbasis android yang juga masih terdapat beberapa kekurangan. Diantaranya adalah anggota dapat mengirimkan pesan kedalam grup sehingga informasi penting dapat bercampur dengan informasi yang lainnya.

Pada penelitian ini akan menawarkan sebuah aplikasi yang dapat memberikan informasi yang realtime. Informasi yang dikirimkan bersifat satu arah agar infromasi tidak bercampur dengan yang lain. Dalam informasi dapat disertakan pengingat yang berfungsi untuk mengingatkan pengguna, terdapat fitur pencarian pesan untuk mempermudah pengguna mencari informasi terdahulu, menggunakan teknologi website sebagai 
pengelola data yang dapat diakses oleh admin, juga menggunakan teknologi mobile device berbasis android sebagai client sehingga mudah untuk diakses serta menggunakan API dari Firebase untuk mengirimkan infromasi secara realtime. Penelitian ini menghasilkan aplikasi yang dapat mendukung kebutuhan seperti memberikan informasi secara spesifik secara realtime dan memiliki fitur alarm kegiatan.

\section{PENDAHULUAN}

Dalam dunia Pendidikan, SMS masih marak digunakan untuk menyebarkan inforasi (Nurlaela, Fetty, Sukadi dan Bambang Eka Purnama. 2013). SMS Gateway adalah salah satu media penyebaran informasi berbasis SMS, penggunaan SMS Gateway masih memiliki beberapa kekurangan, diantaranya adalah membutuhkan pulsa sebagai media pengirimnya. Semakin berkembangnya teknologi, muncul berbagai media pengiriman pesan berbasis android yang bisa membuat grup chat. namun pada media pengiriman pesan berbasis android ini masih terdapat beberapa kekurangan. Diantaranya adalah semua anggota yang ada dalam grup dapat mengirimkan pesan, sehingga pesan yang penting akan bercampur dengan pesan yang lain. Admin grup juga harus menyimpan data anggota terlebih dahulu untuk memasukkan anggota kedalam grup. Untuk itu peneliti berencana membuat aplikasi untuk menanggulangi beberapa kekurangan tersebut. Dengan menggunakan aplikasi mobile device berbasis android sebagai client dan website sebagai pengelola data, peneliti berencana untuk membuat aplikasi penyebaran informasi kampus berbasis firebase cloud messaging.

\section{ANALISIS DAN PERANCANGAN}

\subsection{Analisis Kebutuhan Sistem}

1) Kebutuhan Perangkat Keras

Adapun kebutuhan keras untuk membagun aplikasi ini adalah PC/ Laptop dengan spesifikasi OS Windows 1064 bit, RAM minimal 4 GB, ruang hardisk yang tersisa minimal 2 GB, VGA, keyboard dan mouse. Juga membutuhkan android dengan OS Marsmellow. Adapun kebutuhan untuk dapat mengaplikasikan aplikasi adalah server/PC yang dionlinekan untuk menyimpan data website yang akan diakses oleh admin dengan spesifikasi minimal penyimpanyan yang tersisa adalah 2GB. Laptop/PC yang terkoneksi dengan jaringan internet untuk mengakses website dan android dengan spesifikasi RAM minimal 512 MB yang digunakan oleh client menerima notifikasi.

\section{2) Kebutuhan Perangkat Lunak}

Pembuatan aplikasi penyebaran infromasi kampus berbasis Firebase Cloud Messaging membutuhkan beberapa software. Diantaranya adalah :

a) PHP sebagai Perangkat lunak Bahasa Pemrograman

b) Perangkat lunak XAMPP sebagai web server

c) MySQL sebagai perangkat lunak database

d) Sistem Operasi Windows 10 sebagai sistem operasinya

e) PhpMyAdmin sebagai editor database

f) Google Chrome sebagai web browser

g) Sublime Text 3 sebagai editor teks

h) Android Studio sebagai tool untuk membangun aplikasi android

i) corelDrawX7 digunakan untuk desain rancangan progam

Sedangkan untuk pengaplikasian membutuhkan perangkat lunak seperti server, sistem operasi (windows/linux), PHP dan juga MySQL.

\subsection{Metode Pengumpulan Data}

Pengumpulan data dilakukan dengan berbagai metode, antara lain : 
1. Studi Pustaka

Penulis mengumpulkan data dan informasi dengan cara membaca dan mempelajari bukubuku, referensi serta situs-situs penyedia layanan yang berkaitan dengan judul.

2. Observasi

Berdasarkan pengamatan peneliti, media penyebaran informasi yang ada masih kurang efesien. Penyebaran informasi yang menggunakan media SMS Gateway, masih memiliki beberapa kekurangan.

3. Analisis

Peneliti mengemati alur serta media peneyebaran informasi secara sistematis yang digunakan di kampus.

\subsection{Perancangan Proses Sistem}

Pada perancangan proses sistem, peneiti menggunakan DFD level konteks untuk menggambarkan rancangan alur proses sistem dengan melibatkan entitas-entiras secara keseluruhan. Berikut gambar DFD level konteks sistem :

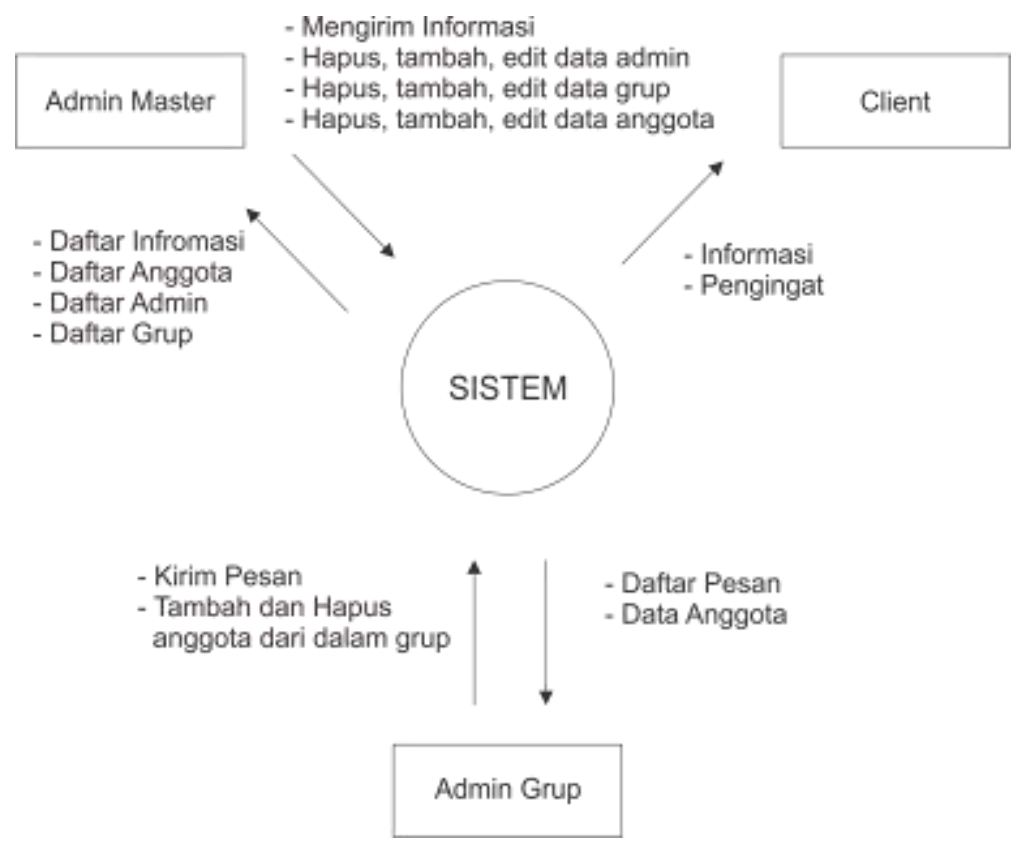

Gambar 1 DFD Level Konteks

Berdasarkan gambar DFD level konteks sistem, terdapat 3 entitas dalam sistem. Admin master, admin grup dan client. Admin master memilik hak akses lebih banyak terhadap sistem dibandingkan dengan hak akses admin grup.

\subsection{Perancangan Interface}

Perancangan Interface adalah perancangan tampilan aplikasi. Berdasarkan platform yang digunakan, sistem mempunyai banyak tampilan. Beberapa diantaranya adalah :

a. Desain Halaman Kirim Pesan: Halaman kirim pesan adalah halaman yang akan diakses setelah admin sukses melakukan login. Halaman ini berfungsi untuk mengirimkan pesan kedalam grup chat. 


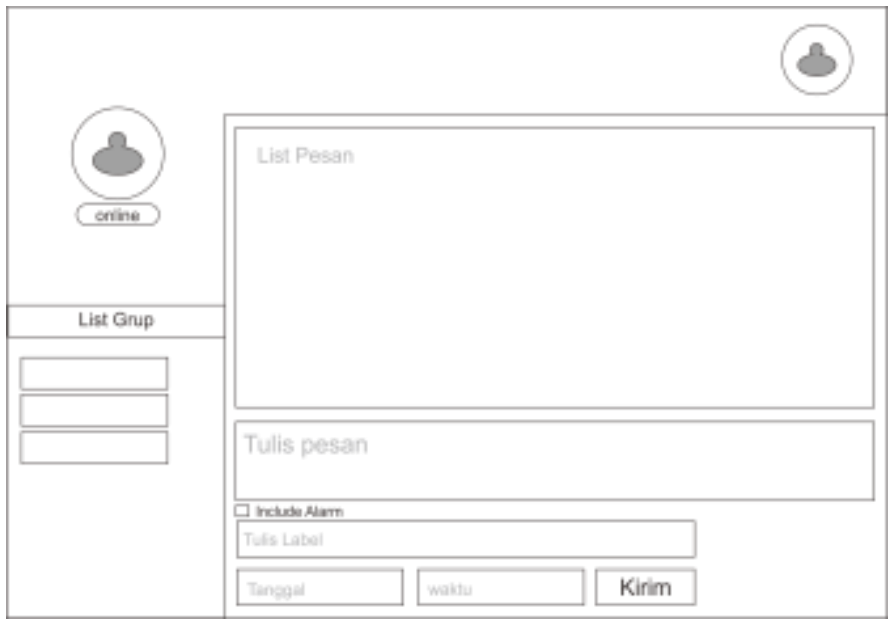

Gambar 2 Halaman kirim pesan

b. Desain Halaman Pengaturan: Pada halaman pengaturan terdapat beberapa menu. Antara lain profil, data grup, data pengelola grup, dan data mahasiswa.

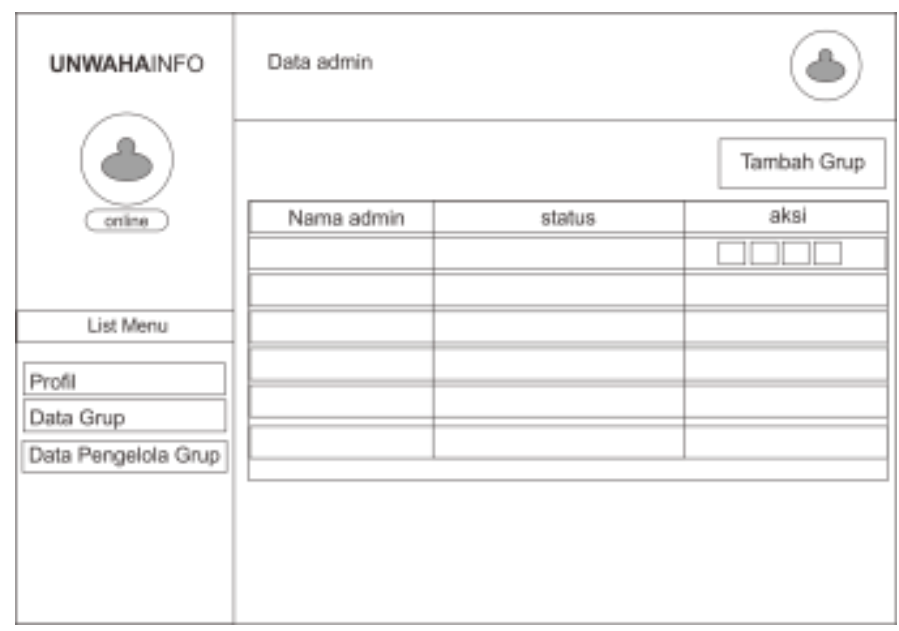

Gambar 3 Halaman pengaturan

c. Desain Halaman List Grup: Halaman list grup berisi daftar grup yang diikuti oleh client. Semakin banyak grup yang diikuti, maka list akan semakin banyak.

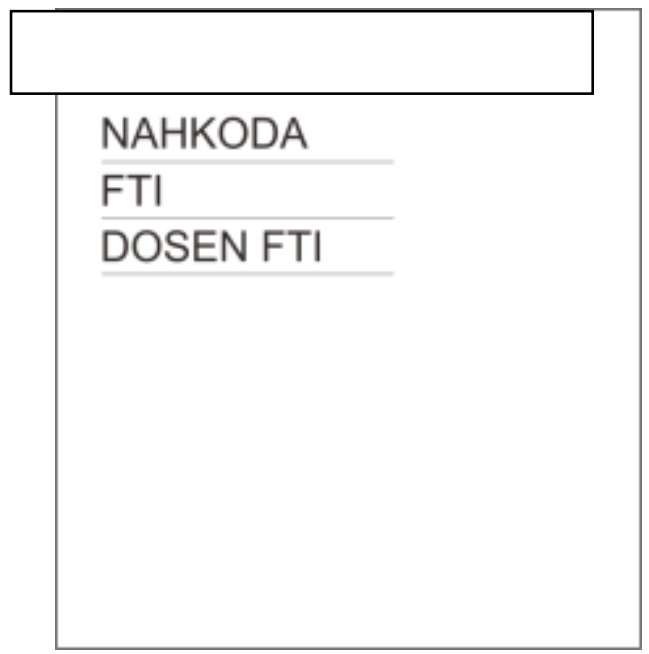

Gambar 4 List grup 


\section{IMPLEMENTASI DAN PEMBAHASAN}

\subsection{Implementasi}

Setelah sistem dianalisis dan didesain, maka langkah selanjutnya adalah melakukan implementasi sistem pada Bahasa pemrogaman. Sehingga sistem siap untuk dioperasionalkan dan pengguna dapat meberikan saran atau masukan untuk pengembangan dimasa depan.

a. Uji Coba Sistem

Untuk menguji sistem, peneliti menggunakan metode black box. Pengujian black box merupakan pengujian progam berdasarkan fungsi dari progam. Berikut table uji coba sistem dengan metode blackbox

\begin{tabular}{|c|l|l|c|}
\hline No. & \multicolumn{1}{|c|}{ Menu/Perintah } & \multicolumn{1}{c|}{ Pengujian } & Hasil \\
\hline 1. & Login admin & Masuk halaman utama. & Berhasil \\
\hline 2. & Tambah grup & Data grup bertambah & Berhasil \\
\hline 3. & Tambah admin & Data admin bertambah & Berhasil \\
\hline 4. & Edit grup & Data grup berubah & Berhasil \\
\hline 5. & Edit admin & Data admin berubah & Berhasil \\
\hline 6. & Hapus grup & Data grup terhapus & Berhasil \\
\hline 7. & Hapus admin & Data admin terhapus & Berhasil \\
\hline 8. & Tambah anggota dalam grup & Anggota grup bertambah & Berhasil \\
\hline 9. & Hapus anggota dari grup & Anggota grup terhapus & Berhasil \\
\hline 10. & Tambah anggota baru & Data anggota bertambah & Berhasil \\
\hline 11. & Import anggota & Data anggota bertambah & Berhasil \\
\hline 12. & Kirim pesan & List pesan bertambah & Berhasil \\
\hline 13. & Login user & Masuk layout utama & Berhasil \\
\hline 14. & Terima pesan & Notifikasi masuk & Berhasil \\
\hline 15 & List grup & Menampilkan list grup & Berhasil \\
\hline 15. & List pesan & Menampilkan list pesan & Berhasil \\
\hline
\end{tabular}

Tabel 1 Hasil pengujian sistem

\subsection{User Interface}

User interface adalah tampilan hasil implementasi dari analisis dan perancangan desain. Berikut beberapa tampilan user interface sistem : 
a. Tampilan halaman kirim pesan

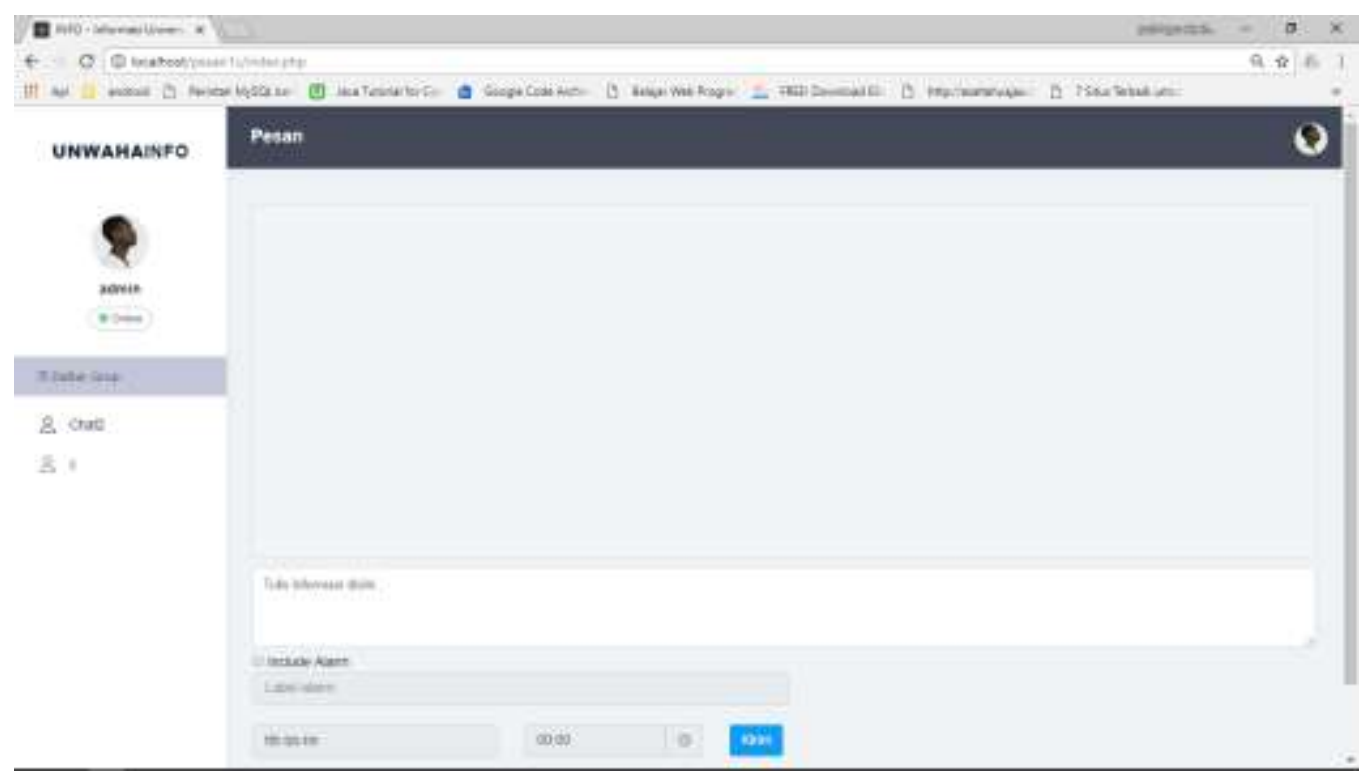

Gambar 5 Tampilan halaman kirim pesan

b. Tampilan halaman pengaturan

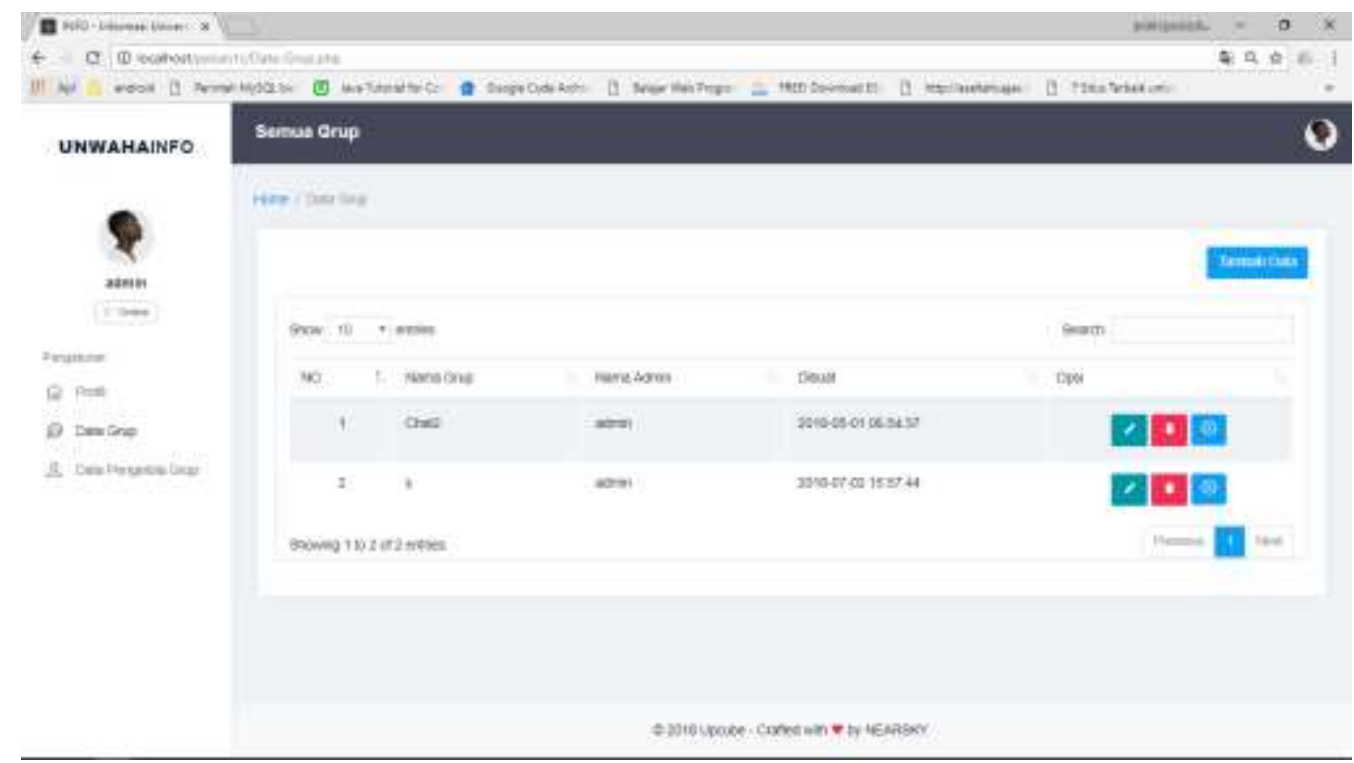

Gambar 6 Tampilan halaman pengaturan 
c. Tampilan list grup

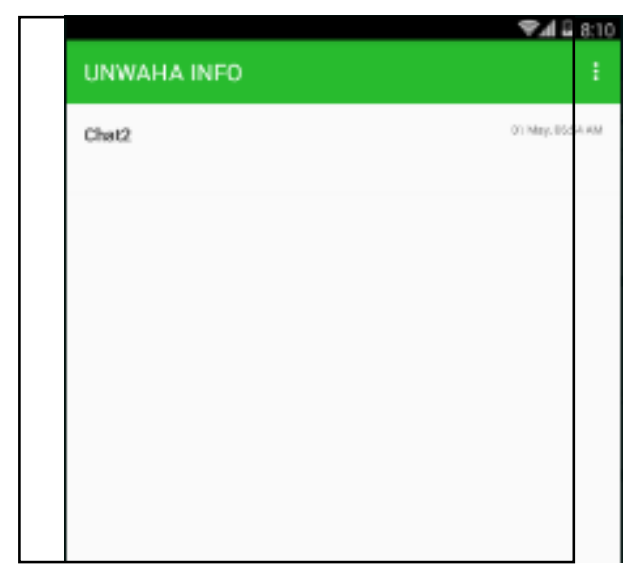

Gambar 7 List grup

\section{KESIMPULAN}

Berdasarkan hasil analisis, perancangan, implementasi dan pengujian dengan menggunakan metode black box, aplikasi penyebaran informasi berbasis Firebase Cloud Messaging dapat mengirimkan informasi secara realtime menggunakan teknologi android. dengan demikian dapat diambil kesimpulan bahwa teknologi android telah berhasil singkron dengan Firebase Cloud Messaging. Hasil pengujian menggunakan metode black box menunjukkan tidak terdapat kesalahan fungsi dan logika pada sistem, sehingga sistem layak untuk diimplementasikan sebagai media penyebaran infromasi yang realtime. 


\section{DAFTAR PUSTAKA}

Afrizal, Ali Subhan. 2017. Rancang Bangun Aplikasi Pembelajaran Dasar Pemrograman Berbasis Mobile Phone. Jurnal Teknik Informatika Politeknik Sekayu (TIPS). Vol. 6, No. 1 (ISSN: 2407-2192)

Cristiano, Wahyu, Justinus Andjarwirawan dan Andreas Handojo. 2013. Aplikasi Broadcast Learning System pada Mobile Device Berbasis Android. Surabaya : Universitas Kristen Petra. Vol. 1 No. 2

Irsan, Muhammad. 2015. Rancang Bangun Aplikasi Mobile Notifikasi Berbasis Android untuk Mendukung Kinerja di Instansi Pemerintah. Pontianak : Universitas Tanjungpura

Nurlaela, Fetty, Sukadi dan Bambang Eka Purnama. 2013. Aplikasi SMS Gateway Sebagai Sarana Penunjang Informasi Perpustakaan Pada Sekolah Menengah Pertama Negeri 1 Arjosari. Surakarta : Universitas Surakarta. Vol. 1 No. 1

Ramadan D. N., Agus Ganda Permana dan Hafidudin. 2017. Perancangan Dan Realisasi Mobil Remote Control Menggunakan Firebase. Bandung : Jurnal Elektro Telekomunikasi Terapan. Vol. 4, No. 1 (ISSN: 2442-4404)

Santoso, Agus dan Andreas Handojo. 2014. Pembuatan Aplikasi Mobile Broadcast Informasi Perkuliahan Berbasis Android. Surabaya : Universitas Kristen Petra. Vol.2 No.1

Setiawan, Jefferson, Edy Kristianto dan Fredicia. 2015. Implementasi Push Notification Pada Informasi Perkuliahan Dan Kegiatan Mahasiswa Berbasis Android. Jakarta: Jurnal Teknik dan Ilmu Komputer. Vol. 4, No. 14

Sonwane, Sanket, Sunil Takalkar, Suraj Kalyankar, Kuldip Wanare, Suraj Baviskar. 2017. Doctor Patient Data Sharing Using Android Chat Application. International Journal of Recent Trends in Engineering \& Research (IJRTER). Vol. 3, Issue 4 (ISSN: 2455-1457)

Sulistyowati, Rini. 2014. Pengaruh Konseling Dan Foot Hand Massage Terhadap Pelaksanaan Mobilisasi Dini Pada Pasien Post Sectio Caesarea. Surakarta:Universitas Sebelas Maret.

Wijaya, C.I., Andreas Handojo dan Anita Nathania Purbowo. 2015. Aplikasi Committee Recruitment Broadcast di Universitas Kristen Petra Berbasis Website dan Facebook API. Surabaya : Universitas Kristen Petra. Vol. 3, No. 2 